\title{
Co-detección de Patógenos Periodontales en Pacientes Chilenos con Periodontitis Crónica
}

\author{
Co-detection of Periodontal Pathogens in Chilean Patients \\ with Chronic Periodontitis
}

Mujica Troncoso $C^{1}$, Castillo-Ruiz $\mathrm{M}^{1}$, Daille $\mathrm{LK}^{1}$, Fuentevilla IA ${ }^{1}$, Bittner $\mathrm{M}^{1,2}$

\begin{abstract}
RESUMEN
Las enfermedades periodontales asociadas a la placa dental son un importante problema de salud pública. La etiología de estas patologías es de origen multifactorial e involucra factores del hospedero, medio ambiente y de carácter infeccioso asociados a bacterias embebidas en la placa dental. Las principales bacterias asociadas a la periodontitis crónica son Porphyromonas gingivalis, Treponema denticola y Tannerella forsythia, mientras que Aggregatibacter actinomycetemcomitans se ha asociado principalmente a la periodontitis agresiva. Otro microorganismo clave en el desarrollo de la enfermedad es Fusobacterium nucleatum, el cual tiene la capacidad de co-agregarse con los patógenos periodontales y así facilitar su colonización. Para demostrar la prevalencia de estas bacterias, la co-detección y la asociación entre pacientes chilenos fumadores y no fumadores, se analizaron 67 muestras mediante PCR convencional. Los resultados mostraron que un $90 \%$ de las muestras fueron positivas para $F$. nucleatum, siendo la bacteria más detectada. Al analizar la co-detección entre las distintas bacterias se observa que $F$. nucleatum está presente en más de un $80 \%$ de los casos cuando se detecta cualquiera de las cuatro bacterias restantes, mientas que A. actinomycetemcomitans se detecta en no más de un $20 \%$ al amplificar cualquiera de las bacterias restantes. Por otra parte, los resultados por género indican que existen diferencias significativas en la detección de $T$. forsythia, F. nucleatum y A. actinomycetemcomitans. Al considerar el factor de tabaquismo se observó que ninguna de las muestras de pacientes fumadores resultó ser positiva para $A$. actinomycetemcomitans.
\end{abstract}

Rev. Clin. Periodoncia Implantol. Rehabil. Oral Vol. 3(3); 118-122, 2010.

Palabras clave: Periodontitis, PCR, co-detección, género.

\begin{abstract}
Periodontal disease associated with dental plaque is a major public health problem. The etiology of these disorders is multifactorial involved seeing host factors, environmental factors and infectious nature associated with the presence of bacteria belonging to the plaque. The main bacteria associated with chronic periodontitis are Porphyromonas gingivalis, Treponema denticola and Tannerella forsythia, while Aggregatibacter actinomycetemcomitans is mainly associated with aggressive periodontitis. Another key organism in the development of the disease is Fusobacterium nucleatum, which has the ability to co-aggregate with other periodontal pathogen. To demonstrate the prevalence of these bacteria and the association between chilean smokers and nonsmokers patients, 67 samples were analyzed by conventional PCR. The results showed that $90 \%$ of the samples were positive for $F$. nucleatum being the most commonly detected bacteria. By analyzing the co-detection between different bacteria shows that $F$. nucleatum is present in more than $80 \%$ of cases when it detects any of the four remaining bacteria, which lie $A$. actinomycetemcomitans was detected in no more than $20 \%$ by amplifying any remaining bacteria. Moreover the results by gender indicate that significant differences exist in the detection of $T$. forsythia, $F$. nucleatum and $A$. actinomycetemcomitans. In considering the factor of smoking was observed that none of the samples from smokers was found to be positive for $A$. actinomycetemcomitans.
\end{abstract}

Rev. Clin. Periodoncia Implantol. Rehabil. Oral Vol. 3(3); 118-122, 2010.

Key words: Periodontitis, PCR, co-detection, gender.

\section{INTRODUCCIÓN}

Las enfermedades de la cavidad oral son un grave problema de salud pública a nivel mundial, dada su alta prevalencia en todos los grupos etáreos ${ }^{(1)}$. Las enfermedades periodontales se pueden definir como cualquier alteración de los tejidos que rodean y dan soporte al diente. Las manifestaciones clínicas de esta enfermedad pueden ser agrupadas bajo la denominación de gingivitis y periodontitis. La gingivitis, la forma más leve de la enfermedad, corresponde a una inflamación de los tejidos blandos del diente, fundamentalmente la encía. Por el contrario, el término periodontitis se utiliza para definir la destrucción progresiva de estructuras periodontales tales como el ligamento periodontal, tejido conectivo gingival y hueso alveolar ${ }^{(2)}$. La etiología de estas patologías es multifactorial, viéndose involucrados factores del hospedero, del ambiente y factores de carácter infeccioso asociados a la presencia de la placa dental. La placa dental ha sido definida como una comunidad de diversos microorganismos adheridos a la superficie del diente como una biopelícula y puede ser dividida de acuerdo a su localización en supragingival y subgingival ${ }^{(3,4)}$. La estructura y patogenicidad de la placa subgingival es intensamente estudiada y se estima que existirían cerca de 700 especies bacterianas dentro de la biopelícula oral en humanos, aunque todavía no está claro como éstas compiten, coexisten y/o

1. Laboratorio de Microbiología y Biotecnología Oral. Facultad de Ciencias Biológicas, Universidad Andrés Bello. Santiago, Chile.

2. Facultad de Odontología. Universidad Andrés Bello. Santiago, Chile.

Correspondencia autor: Dr. Mauricio Bittner Ortega. mbittner@unab.cl. Laboratorio de Microbiología y Biotecnología Oral. Universidad Andrés Bello. Echaurren 237. Santiago, Chile.

Financiamiento: Este trabajo fue financiado por los proyectos UNAB 48-09/R, UNAB DI 24-09/I y la beca de apoyo de tesis doctoral otorgada al becario AT-24100063. Trabajo recibido el 03/11/2010. Aprobado para su publicación el 26/12/2010. 
cooperan para iniciar este proceso infeccioso crónico $^{(5)}$. Del análisis de la microflora oral se ha establecido que los microorganismos dentro de la placa subgingival estarían formando grupos o complejos microbianos ${ }^{(6-9)}$. Hasta la fecha se han descritos 6 complejos: complejo azul, amarillo, verde, morado, naranja y rojo. El complejo rojo se incorpora tardíamente en el desarrollo de la biopelícula y las especies que lo comprenden, consideradas los principales agentes etiológicos de la peridontitis crónica, son Porphyromonas gingivalis, Treponema denticola y Tannerella forsythia. Un microorganismo clave en la formación de esta placa dental es Fusobacterium nucleatum, que pertenece al complejo naranja, el cual se sugiere que actúa como un "puente" microbiano entre los colonizadores tempranos y los colonizadores tardíos durante la formación de la biopelícula. Esta capacidad se debe a su habilidad para co-agregarse con los patógenos periodontales mencionados y así facilitar su colonización. Numerosos trabajos han descrito que la interacción con Porphyromonas gingivalis mejoraría la unión de la última a células del hospedero ${ }^{(10,11)}$. La periodontitis se puede presentar, además, como un cuadro menos frecuente, pero mucho más severo conocido como periodontitis agresiva. Esta manifestación clínica ha sido asociada con la presencia de Aggregatibacter actinomycetemcomitans, otro patógeno periodontal que sin embargo no se encuentra dentro de los complejos descritos anteriormente ${ }^{(12,13)}$.

Durante los últimos 20 años numerosas investigaciones han demostrado epidemiológicamente y biológicamente que el tabaquismo es un importante factor de riesgo involucrado con el desarrollo y progresión de la enfermedad periodontal. Actualmente, el mecanismo específico de los efectos nocivos del tabaco no se encuentra completamente dilucidado, pero se ha asociado a la alteración y modificación de los factores de respuesta tanto microbiana como del hospedero ${ }^{(14,15)}$.

La distribución de los patógenos periodontales difiere en relación a la ubicación geográfica y al grupo racial/étnico, por lo que en este estudio se planteó como objetivo identificar mediante PCR convencional la prevalencia y asociación que existe entre la detección de Fusobacterium nucleatum, Aggregatibacter actinomycetemcomitans y bacterias del complejo rojo en personas con periodontitis crónica en Chile. Además de establecer una relación entre la presencia de estas bacterias en personas fumadoras y no fumadoras.

\section{MATERIALES Y MÉTODOS}

\section{Población en Estudio}

El estudio incluyó a 67 pacientes periodontalmente enfermos, sin tratamiento periodontal previo, diagnosticados en la Clínica Odontológica de la Universidad Andrés Bello en Santiago, Chile. Los pacientes fueron seleccionados y divididos en grupos según género, rango etáreo y la condición de fumador o no fumador (Tabla 1).

Tabla 1. Distribución de pacientes según género y tabaquismo.

\begin{tabular}{|l|c|c|c|c|c|c|}
\hline \hline & \multicolumn{3}{|c|}{ Femenino (n=36) } & \multicolumn{3}{c|}{ Masculino (n=31) } \\
\cline { 2 - 7 } & $\begin{array}{c}\text { Grupo 1 } \\
\mathbf{3 5 - 4 9} \\
\text { años }\end{array}$ & $\begin{array}{c}\text { Grupo 2 } \\
\mathbf{5 0 - 6 4} \\
\text { años }\end{array}$ & $\begin{array}{c}\text { Grupo 3 } \\
\geq 65 \\
\text { años }\end{array}$ & $\begin{array}{c}\text { Grupo 1 } \\
\mathbf{3 5 - 4 9} \\
\text { años }\end{array}$ & $\begin{array}{c}\text { Grupo 2 } \\
\mathbf{5 0 - 6 4} \\
\text { años }\end{array}$ & $\begin{array}{c}\text { Grupo 3 } \\
\geq 65 \\
\text { años }\end{array}$ \\
\hline Edad & $\begin{array}{c}33.3 \% \\
(n=12)\end{array}$ & $\begin{array}{c}61 \% \\
(n=22)\end{array}$ & $\begin{array}{c}5.6 \% \\
(n=2)\end{array}$ & $\begin{array}{c}9.7 \% \\
(n=3)\end{array}$ & $\begin{array}{c}80.6 \% \\
(n=25)\end{array}$ & $\begin{array}{c}9.7 \% \\
(n=3)\end{array}$ \\
\hline Fumador & $\begin{array}{c}41.7 \% \\
(n=5)\end{array}$ & $\begin{array}{c}18.2 \% \\
(n=4)\end{array}$ & $\begin{array}{c}0.0 \% \\
(n=0)\end{array}$ & $\begin{array}{c}33.3 \% \\
(n=3)\end{array}$ & $\begin{array}{c}40 \% \\
(n=10)\end{array}$ & $\begin{array}{c}0.0 \% \\
(n=0)\end{array}$ \\
\hline
\end{tabular}

\section{Toma de Muestra Microbiológica}

Las muestras fueron recolectadas desde la placa subgingival de pacientes con periodontitis crónica, con profundidades de sondaje superior o iguales a $6 \mathrm{~mm}$. La obtención de la muestra se realizó según Gajardo y cols. ${ }^{(16)}$ con algunas modificaciones. Brevemente se insertaron 2 conos de papel estériles estandarizados $N^{\circ} 30$ durante 20 segs. Desde cada paciente se tomaron muestras desde los 3 sitios más profundos. Las muestras de cada paciente fueron transportadas a $-20^{\circ} \mathrm{C}$ al Laboratorio de Microbiología y Biotecnología Oral de la Facultad de Odontología de la Universidad Andrés Bello y procesadas dentro de las primeras $24 \mathrm{hrs}$ de almacenamiento.

\section{Reacción en Cadena de la Polimerasa (PCR)}

Para realizar el análisis por PCR cada cono de papel se lavó con $100 \mu \mathrm{L}$ de agua destilada estéril con el fin de desprender las bacterias. Para la liberación del material genético, la suspensión bacteriana se lisó por denaturación a $100^{\circ} \mathrm{C}$ durante $10 \mathrm{~min}$. En cada muestra se analizó por separado la presencia de los patógenos periodontales $F$. nucleatum $(F n), P$. gingivalis $(P g)$, $T$. denticola $(T d), T$. forsythia $(T f)$ y A. actinomycetemcomitans $(A a)$. Para la identificación de cada bacteria se amplificó un fragmento del gen 16S rDNA utilizando los partidores descritos en la Tabla $2^{(17-19)}$. La reacción de PCR se llevó a cabo en un volumen final de $20 \mu \mathrm{l}$. Las concentraciones de cada componente fueron: $0.5 \mathrm{U}$ de GoTaq Flexi DNA Polymerase (Promega, USA), $1.5 \mathrm{mM} \mathrm{MgCl}$, $2 \mathrm{mM}$ de cada dioxinucleosido trifosfato (dNTP), $1 \mu \mathrm{M}$ de cada partidor y $0.5 \mu \mathrm{g}$ de DNA. Todas las reacciones de PCR fueron realizadas en un Termociclador Multigene (Labnet Inc.). El programa de PCR utilizado fue: denaturación inicial por $10 \mathrm{~min}$ a $94^{\circ} \mathrm{C}$; 35 ciclos de $94^{\circ} \mathrm{C}$ por 30 segs, $55^{\circ} \mathrm{C}$ por 30 segs y $72^{\circ} \mathrm{C}$ por 30 segs; y una extensión final a $72^{\circ} \mathrm{C}$ durante $10 \mathrm{~min}$. Los productos fueron separados por electroforesis en gel de agarosa al $1.5 \%$ y visualizados por tinción con bromuro de etidio.

Tabla 2. Partidores utilizados en este estudio.

\begin{tabular}{|c|c|c|c|}
\hline Bacteria & Secuencia (5'-3') & Tamaño (pb) & Referencia \\
\hline \multirow{2}{*}{$\begin{array}{c}\text { Treponema denticola } \\
(T d)\end{array}$} & taa tac cga atg tgc tca ttt aca t & \multirow[t]{2}{*}{316} & \multirow{2}{*}{$\begin{array}{l}\text { Okada et al., } \\
2001\end{array}$} \\
\hline & tac aag aag cat tcc ctc ttc ttc tta & & \\
\hline \multirow{2}{*}{$\begin{array}{c}\text { Tannerella forsythia } \\
\text { (Tf) }\end{array}$} & tac agg gga ata aaa tga gat acg & \multirow[t]{2}{*}{745} & \multirow{6}{*}{$\begin{array}{c}\text { Tran \& Rudney, } \\
1999\end{array}$} \\
\hline & acg tca tcc cca cct tcc tc & & \\
\hline \multirow{2}{*}{$\begin{array}{l}\text { Porphyromonasgingivalis } \\
\text { (Pg) }\end{array}$} & tgt aga tga ctg aaa acc & \multirow[t]{2}{*}{197} & \\
\hline & acg tca tcc cca cct tcc tc & & \\
\hline \multirow{2}{*}{$\begin{array}{l}\text { A adinomyoctemoomians } \\
\text { (Aa) }\end{array}$} & attg ggg ttt agc cct ggt g & \multirow[t]{2}{*}{360} & \\
\hline & acg tca tcc cca cct tcc tc & & \\
\hline \multirow{2}{*}{$\begin{array}{l}\text { Fusobacteriumnudeatum } \\
\text { (Fn) }\end{array}$} & gga ttt att ggg cgt aaa gc & \multirow[t]{2}{*}{167} & \multirow{2}{*}{$\begin{array}{l}\text { Boutaga y cols., } \\
2005\end{array}$} \\
\hline & ggc att cct aca aat atc tac gaa & & \\
\hline
\end{tabular}

\section{Análisis Estadístico}

Para comparar los parámetros entre los distintos grupos y la prevalencia de los patógenos periodontales se calculó el intervalo del $95 \%$ de confianza y se realizó la comparación de medias a través del t-Test, utilizando el programa estadístico SPSS versión 17.0.

\section{RESULTADOS}

Mediante el uso de reacciones individuales de PCR, se detectó la presencia de los principales patógenos periodontales presentes en el surco periodontal de pacientes con periodontitis crónica. Utilizando el gen 16S rDNA como un marcador genético para las bacterias en estudio se observaron fragmentos especie-específicos para $P$. gingivalis $(P g)$, T. denticola $(T d)$, F. nucleatum $(F n)$, T. forsythia $(T f)$ y $A$. actinomycetemcomitans $(A a)$. De las 67 muestras de pacientes analizadas, 39 de ellas fueron positivas para $T d, 20$ para $T f, 21$ para $P g$, 60 para Fn y 11 para Aa (Figura 1). En 3 muestras no se detectó ninguna de las bacterias analizadas. Al analizar la co-detección entre las distintas bacterias se observa que Fn está presente en más de un $80 \%$ de los casos cuando se detecta cualquiera de las cuatro bacterias restantes. Diferente es el caso de Aa donde se observa que no se detecta en más de un $20 \%$ al amplificar cualquiera de las bacterias restantes (Tabla 3). Al analizar la incidencia de los patógenos periodontales por género se observan diferencias significativas en la detección de $T f, F n$ y Aa, siendo mayor la incidencia en mujeres (Figura 2). Estas diferencias en la incidencia por género se analizaron mayormente para determinar si existe una relación con la co-detección de otros patógenos periodontales (Figura 3). Al incorporar el factor de tabaquismo, se observa que ninguna de las muestras provenientes de pacientes fumadores resultó ser positiva para Aa (Figura 4). 
Tabla 3. Porcentajes de detección de $P$. gingivalis, T. denticola, F. nucleatum, $T$. forsythia y A. actinomycetemcomitans asociado a la co-detección a un segundo patógeno periodontal.

\begin{tabular}{|l|c|c|c|c|c|}
\hline \hline \multirow{2}{*}{ Patógeno Principal } & \multicolumn{5}{|c|}{ Bacteria Asociada a la Co-detección } \\
\cline { 2 - 6 } & $\boldsymbol{T d}$ & $\boldsymbol{T f}$ & $\boldsymbol{P g}$ & $\boldsymbol{F n}$ & $\boldsymbol{A a}$ \\
\hline T. denticola & - & $38 \%$ & $38 \%$ & $92 \%$ & $21 \%$ \\
\hline T. forsythia & $75 \%$ & - & $55 \%$ & $80 \%$ & $20 \%$ \\
\hline P. gingivalis & $71 \%$ & $52 \%$ & - & $95 \%$ & $19 \%$ \\
\hline F. nucleatum & $60 \%$ & $33 \%$ & $33 \%$ & - & $18 \%$ \\
\hline A. actinomycetemconitans & $73 \%$ & $36 \%$ & $36 \%$ & $100 \%$ & - \\
\hline
\end{tabular}

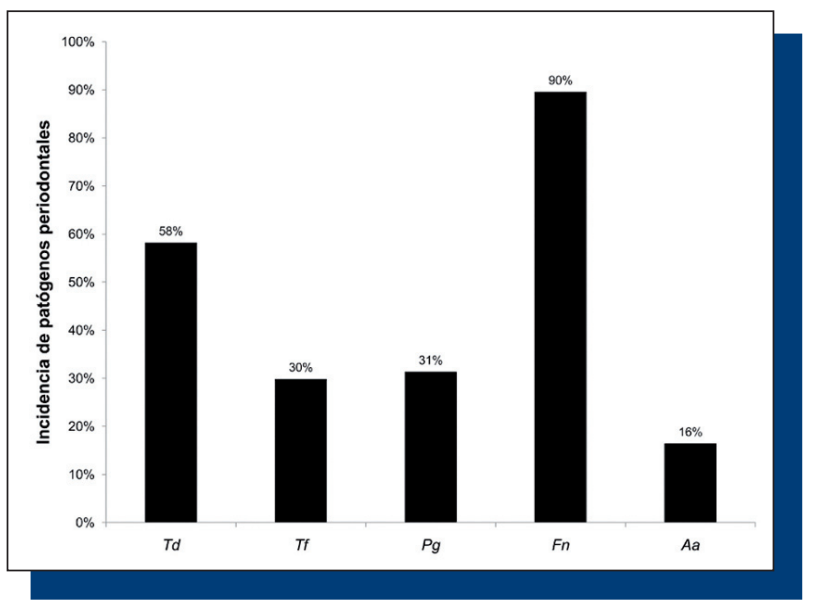

Figura 1. Porcentaje de incidencia de patógenos periodontales detectados en 67 pacientes de la Clínica Odontológica durante el año 2009.

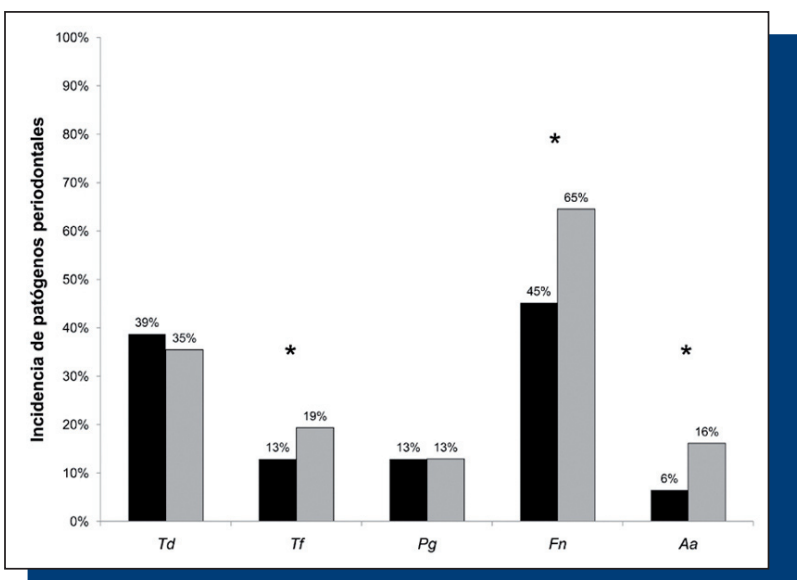

Figura 2. Porcentajes de detección de P. gingivalis, T. denticola, F. nucleatum, T. forsythia y $A$. actinomycetemcomitans asociado a género. ( $\square$ ) Hombres ( $\square$ ) Mujeres $\left({ }^{*} \mathrm{p}<0.05\right)$.

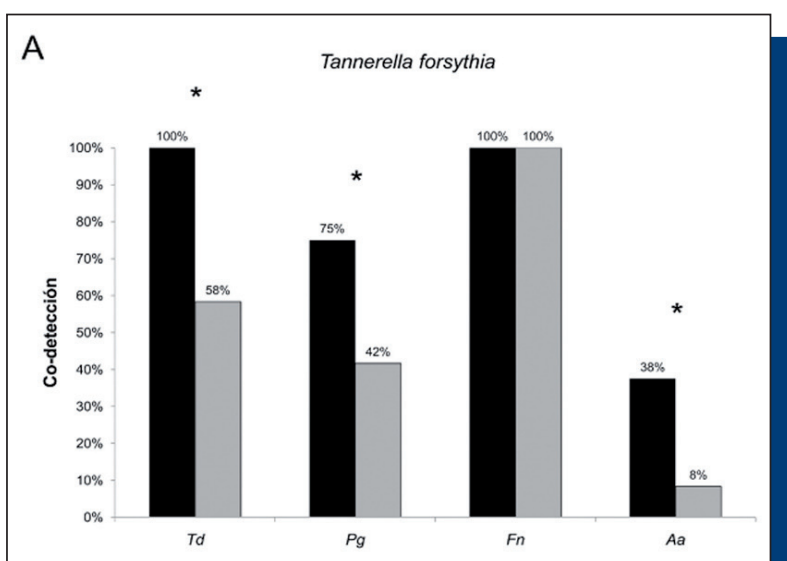

B

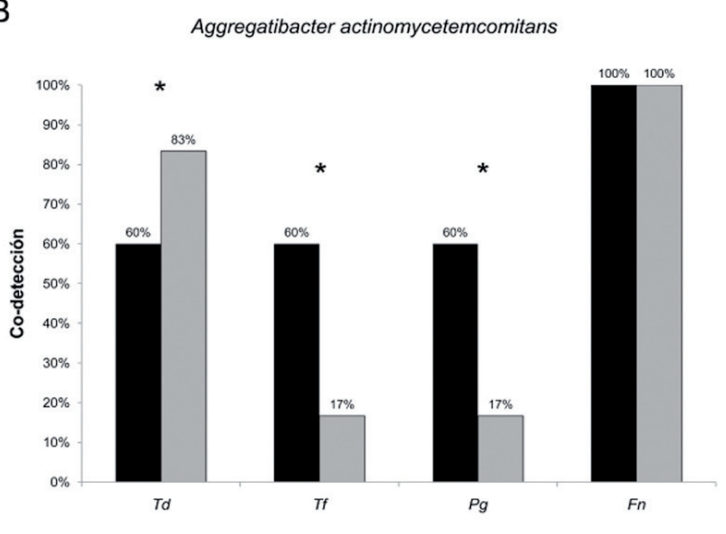

C

Fusobacterium nucleatum

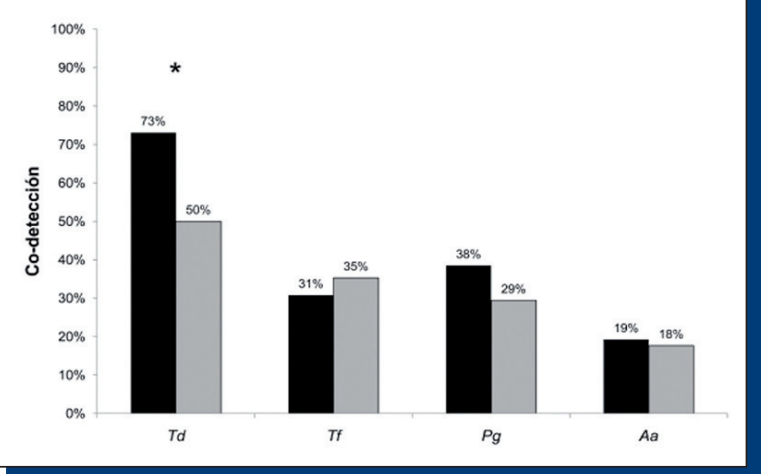

Figura 3. Porcentajes de detección de P. gingivalis, T. denticola, F. nucleatum, T. forsythia y A. actinomycetemcomitans asociado al género en muestras que presentan: (A) Tannerella forsythia. (B) Aggregatibacter actinomycetemcomitans. (C) Fusobacterium nucleatum. (ロ) Hombres ( $\square$ ) Mujeres ( $\left.{ }^{*} p<0.05\right)$.

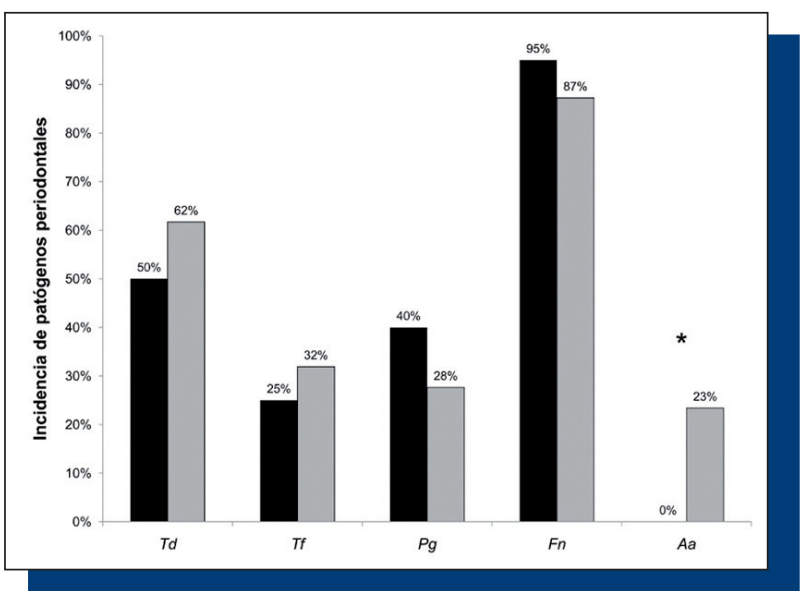

Figura 4. Porcentajes de detección de P. gingivalis, T. denticola, F. nucleatum, T. forsythia y $A$. actinomycetemcomitans asociado al tabaquismo. (๘) Fumador ( $\square$ ) No fumador ( $\left.{ }^{*} \mathrm{p}<0.05\right)$. 


\section{DISCUSIÓN}

Está ampliamente aceptado que la periodontitis corresponde a una enfermedad infecciosa y multifactorial, donde un consorcio microbiano modula el sistema inmune de un hospedero susceptible para causar daño sobre los tejidos de soporte y protección de las piezas dentales ${ }^{(20,21)}$. Además de modular, existe un grupo de bacterias, denominadas patógenos periodontales, que dañan directamente estos tejidos mediante la expresión de diferentes factores de virulencia donde destacan lipopolisacáridos, toxinas y proteasas extracelulares ${ }^{(22)}$. Sin embargo, una de las etapas claves que posee cualquier enfermedad infecciosa, donde no se excluyen las enfermedades periodontales, corresponde a la colonización. Este proceso incluye normalmente la expresión de fimbrias y exopolisacáridos que permiten a las bacterias adherirse firmemente y de manera específica a diferentes tipos celulares. En este contexto, Fusobacterium nucleatum, un bacilo Gram negativo alargado y anaerobio, juega un papel bastante importante en el proceso de colonización de las bacterias del grupo rojo ( $P$. gingivalis, $T$. forsythia y T. denticola), descritas por Sockranski(8) como los principales patógenos periodontales. Por esta razón en este trabajo se analizó la presencia conjunta de los diferentes patógenos periodontales y F. nucleatum. Para esto se analizaron 67 pacientes diagnosticados con periodontitis crónica generalizada atendidos durante el año 2009 en la Clínica Odontológica de la Universidad Andrés Bello. En la Tabla 1 se muestra la distribución porcentual entre hombres y mujeres y el rango etáreo de los pacientes, donde se observa que la enfermedad afecta mayoritariamente a personas entre 50 y 64 años de edad, lo que concuerda con lo descrito en literatura ${ }^{(23)}$. Al analizar la presencia de los diferentes patógenos periodontales en el total de pacientes estudiados (Figura 1), se observa que Treponema denticola corresponde a la bacteria del complejo rojo más incidente, resultado que no concuerda con el estudio realizado por Haffajee y cols. en $2004^{(24)}$, donde se concluye que en pacientes chilenos Porphyromonas gingivalis sería el principal patógeno periodontal. Este resultado se puede deber a las diferentes técnicas utilizadas para la detección de los diferentes patógenos o bien a diferentes criterios de inclusión y exclusión utilizados en cada estudio. En la Figura 1 se observa, además, la baja incidencia que posee Aggregatibacter actinomycetemcomitans, observación concordante con lo descrito en literatura, ya que normalmente esta bacteria se asocia a la forma agresiva de la periodontitis ${ }^{(25,26)}$, aunque no se ha descartado que juegue un papel importante en la iniciación y progresión de la periodontitis crónica ${ }^{(27)}$. Cabe destacar la alta incidencia que posee F. nucleatum, resultado esperado puesto que aunque no siempre es posible encontrar todos los patógenos en un saco periodontal, todas las bacterias analizadas, tanto las del grupo rojo como $A$. actinomycetemcomitans, interactúan con $F$. nucleatum, coagregándose con ésta para mejorar su colonización ${ }^{(28)}$. En la Tabla 3 se muestra que todas las bacterias analizadas poseen una fuerte asociación con $F$. nucleatum más que con cualquier otro patógeno analizado. Por ejemplo, el $100 \%$ de las veces que se detecta $A$. actinomycetemcomitans, $F$. nucleatum también está presente, similar al caso de $P$. gingivalis, donde el 95 de las veces que se detecta $P$. gingivalis está presente $F$. nucleatum. Este resultado también se observa para $T$. denticola, pero en menor medida ya que los porcentajes van desde un $60 \%$ cuando se detecta F. nucleatum hasta un $75 \%$ cuando se detecta $T$. denticola.

Existe una serie de reportes contradictorios respecto a si la prevalencia o severidad de la enfermedad periodontal afecta más a hombres que a mujeres, pero existen varios reportes que apuntan a que las mujeres poseen una mayor susceptibilidad, pero no se observa a nivel poblacional, puesto que tendrían una mejor higiene que los hombres, un factor muy relevante en el desarrollo de la enfermedad ${ }^{(26,29,30)}$. En la Figura 2 se observa que existen diferencias significativas respecto a la incidencia de $T$. forsythia, A. actinomycetemcomitans y F. nucleatum cuando se analizan los datos utilizando los pacientes separados por género. De este resultado se desprende que las mujeres poseen un incidencia significativamente mayor de las bacterias mencionadas. Al analizar la co-detección de éstos (Figura 3), también se observan diferencias significativas, las que apuntan a una correlación significativamente menor en las mujeres cuando se correlacionan T. forsythia (Figura 3A), A. actinomycetemcomitans (Figura 3B) y F. nucleatum (Figura $3 \mathrm{C}$ ) con los demás patógenos periodontales.

El fenómeno de coagregación y sinergismo microbiano que existe en la placa dental corresponde a un factor muy importante para la progresión de la enfermedad ${ }^{(31)}$, por lo que la co-detección de los diferentes patógenos periodontales debería ser siempre muy alta. En este trabajo se determinó que esto se cumple, pero solamente cuando se analiza la población masculina (Figura $3 \mathrm{~A}$ y $\mathrm{B}$ ), dada la elevada correlación que existe entre $T$. forsythia y $A$. actinomycetemcomitans con las demás bacterias. Tanto la coagregación como el sinergismo microbiano están fuertemente asociados a la presencia de distintos factores de virulencia que posee cada especie bacteriana. Está comprobado que diferentes serotipos dentro de una misma especie poseen diferencias significativas en el grado de virulencia que posee esta bacteria, como lo descrito para los serotipos en base al LPS para A. actinomycetemcomitans o los serotipos capsulares y fimbriales de $P$. gingivalis ${ }^{(32)}$. En este trabajo se detectaron los patógenos periodontales en base a al gen que codifica para el RNA 16S, lo que es realiza a nivel de especie y no discriminaría entre serotipo diferentes. En este contexto, las diferencias significativas observadas para la población masculina respecto a la femenina podrían deberse a que la colonización de los sacos periodontales en los diferentes géneros no es igual y ciertas bacterias se ven favorecidas por el ambiente de uno u otro individuo. Se sabe que los nutrientes disponibles para las bacterias en el saco periodontal es diferente entre hombres y mujeres, principalmente por la concentración hormonal(33). Una explicación de estas característica podría eventualmente llegar a dar cuenta de la diferencia que existe en la incidencia y/o severidad de la enfermedad periodontal que se ha observado entre hombres y mujeres.

Dentro de los factores de riesgo que posee la enfermedad no existe el género, pero si el tabaquismo. En la Figura 4 se observa que no existen diferencias significativas en la detección de bacterias del grupo rojo cuando analiza el efecto del tabaco. Tampoco se observaron diferencias cuando se analizaron los resultados por género ni cuando se analizó la co-detección (datos no mostrados). Sin embargo, sólo se observó la presencia de $A$. actinomycetemcomitans en pacientes no fumadores independiente del género, lo que indicaría que esta bacteria podría verse desfavorecida directa o indirectamente por los efectos del tabaco en el periodonto.

Los resultados de este trabajo sugieren que existe una diferencia significativa en la incidencia de los patógenos periodontales analizados entre hombres y mujeres, lo que podría dar cuenta de las diferencias entre géneros, observadas en los estudios de prevalencia de la enfermedad periodontal. Esto hace necesario saber más sobre las bacterias que se quieren detectar y no sólo detectar su presencia o cantidad relativa en un determinado saco periodontal. Por otra parte, el tabaco parece no ser un factor importante en lo que a microorganismos se refiere, sin embargo dada la baja cantidad de pacientes analizados no se puede concluir que exista una relación.

\section{AGRADECIMIENTOS}

Este trabajo fue financiado por los proyectos UNAB 48-09/R, UNAB DI 24-09/I y la beca de apoyo de tesis doctoral otorgada al becario AT-24100063.

\section{DECLARACIÓN DE INTERÉS}

Los autores declaran no tener conflictos de interés. 


\section{REFERENCIAS BIBLIOGRÁFICAS}

1. Gamonal JA, López NJ, Aranda W. Periodontal conditions and treatment needs, by CPITN, in the 35-44 and 65-74 year-old population in Santiago, Chile. Int Dent J, 1998; 48(2): 96-103.

2. Pihlstrom BL, Michalowicz BS, Johnson NW. Periodontal diseases. Lancet, 2005; 366(9499): 1809-1820.

3. Marsh PD. Dental plaque as a microbial biofilm. Caries Res, 2004; 38(3): 204-211.

4. Nishihara T, Koseki T. Microbial etiology of periodontitis. Periodontol 2000, 2004; 36: 14-26.

5. Paster BJ, Boches SK, Galvin JL, Ericson RE, Lau CN, Levanos VA, Sahasrabudhe A, Dewhirst FE. Bacterial diversity in human subgingival plaque. J Bacteriol, 2001; 183(12): 3770-3783.

6. Dzink JL, Socransky SS, Haffajee AD. The predominant cultivable microbiota of active and inactive lesions of destructive periodontal diseases. J Clin Periodontol, 1988; 15(5): 316-323.

7. Socransky SS, Haffajee AD, Dzink JL. Relationship of subgingival microbial complexes to clinical features at the sampled sites. J Clin Periodontol, 1988; 15(7): 440-444.

8. Socransky SS, Haffajee AD, Cugini MA, Smith C, Kent RL Jr. Microbial complexes in subgingival plaque. J Clin Periodontol, 1998; 25(2): 134144.

9. Socransky SS, Haffajee AD. Periodontal microbial ecology. Periodontol 2000, 2005; 38: 135-187.

10. Metzger Z, Blasbalg J, Dotan M, Weiss El. Enhanced attachment of Porphyromonas gingivalis to human fibroblasts mediated by Fusobacterium nucleatum. J Endod, 2009; 35(1): 82-85.

11. Saito A, Inagaki S, Kimizuka R, Okuda K, Hosaka Y, Nakagawa T, Ishihara K. Fusobacterium nucleatum enhances invasion of human gingival epithelial and aortic endothelial cells by Porphyromonas gingivalis. FEMS Immunol Med Microbiol, 2008; 54(3): 349-355.

12. Slots J. Update on Actinobacillus actinomycetemcomitans and Porphyromonas gingivalis in human periodontal disease. J Int Acad Periodontol, 1999; 1(4): 121-126.

13. Henderson B, Nair SP, Ward JM, Wilson M. Molecular pathogenicity of the oral opportunistic pathogen Actinobacillus actinomycetemcomitans. Annu Rev Microbiol, 2003; 57: 29-55.

14. Heitz-Mayfield LJ, Huynh-Ba G. History of treated periodontitis and smoking as risks for implant therapy. Int J Oral Maxillofac Implants, 2009; 24 Suppl: 39-68

15. Laxman VK, Annaji S. Tobacco use and its effects on the periodontium and periodontal therapy. J Contemp Dent Pract, 2008; 1; 9(7): 97-107.

16. Gajardo M, Silva N, Gómez L, León R, Parra B, Contreras A, Gamonal $\mathrm{J}$. Prevalence of periodontopathic bacteria in aggressive periodontitis patients in a chilean population. J Periodontol, 2005; 76(2): 289-294.

17. Boutaga K, van Winkelhoff AJ, Vandenbroucke-Grauls CM, Savelkoul $\mathrm{PH}$. Periodontal pathogens: A quantitative comparison of anaerobic culture and real-time PCR. FEMS Immunol Med Microbiol, 2005; 45: 191 199.

18. Okada M, Hayashi F, Nagasaka N. PCR detection of 5 putative periodontal pathogens in dental plaque samples from children 2 to 12 years of age. Journal of Clinical Periodontology, 2001; 28: 576-582.

19. Tran SD, Rudney JD. Improved multiplex PCR using conserved and species-specific 16S rRNA gene primers for simultaneous detection of Actinobacillus actinomycetemcomitans, Bacteroides forsythus and Porphyromonas gingivalis. J Clin Microbiol, 1999; 37: 3504-3508.
20. Leibbrandt A, Penninger M. RANK/RANKL: Regulators of immune responsesand bone physiology. Annals New York Academy of Sciences, 2008; 1143: 123-150.

21. Mahanonda R, Pichyangkul S. Toll-like receptors and their role in periodontal health and disease. Periodontology 2000, 2007; 43: 41-55.

22. Kaplan JB, Schreiner HC, Furgang D, Fine DH. Population structure and genetic diversity of Actinobacillus actinomycetemcomitans strains isolated from localized juvenile periodontitis patients. Journal of Clinical Microbiology, 2002; 40: 1181-1187.

23. Khader YS. Factors associated with periodontal diseases in Jordan: principal component and factor analysis approach. J Oral Sci, 2006; 48(2): $77-84$

24. Haffajee AD, Bogren A, Hasturk H, Feres M, López NJ, Socransky SS. Subgingival microbiota of chronic periodontitis subjects from different geographic locations. Journal of Clinical Periodontology, 2004; 31(11): 996-1002.

25. Zambon JJ. Actinobacillus actinomycetemcomitans in human periodontal disease. J Clin Periodontol, 1985; 12(1): 1-20.

26. Cortelli JR, Roman-Torres CV, Aquino DR, Franco GC, Costa FO, Cortelli SC. Occurrence of Aggregatibacter actinomycetemcomitans in Brazilians with chronic periodontitis. Braz Oral Res, 2010; 24(2): $217-$ 223

27. Fine DH, Markowitz K, Furgang D, Velliyagounder K. Aggregatibacter actinomycetemcomitans as an early colonizer of oral tissues: epithelium as a reservoir? J Clin Microbiol, 2010; 48(12): 4464-4473.

28. Bolstad Al, Jensen HB, Bakken V. Taxonomy, biology and periodontal aspects of Fusobacterium nucleatum. Clin Microbiol Rev, 1996; 9(1): 5571.

29. Bourgeois D, Bouchard P, Mattout C. Epidemiology of periodontal status in dentate adults in France, 2002-2003. Journal of Periodontal Research, 2007; 42(3): 219-227.

30. Norderyd O, Hugoson A, Grusovin G. Risk of severe periodontal disease in a Swedish adult population. A longitudinal study. Journal of Clinical Periodontology, 1999; 26(9): 608-615.

31. Hojo K, Nagaoka S, Ohshima T, Maeda N. Bacterial interactions in dental biofilm development. J Dent Res, 2009; 88(11): 982-990.

32. Fine DH, Kaplan JB, Kachlany SC, Schreiner HC. How we got attached to Actinobacillus actinomycetemcomitans: A model for infectious diseases. Periodontol 2000, 2006; 42: 114-157.

33. Klinger G, Glänzer S, Sigusch B, Klinger G, Römer W Pharmazie. Influence of sexual steroids on cell functions of PMNL in the gingival sulcus. Pharmazie, 2000 Sep; 55(9): 678-680. 